\title{
“Detalles”, frustraciones y desconciertos: El trabajo emocional en las
}

\section{parejas jóvenes heterosexuales / 'Little Gestures', Frustrations and}

\section{Bafflement: The emotional work in young heterosexual couples}

\author{
Ana Vicente Olmo \\ Grupo de Estudios Socio-Culturales Contemporáneos (GRESCO), Universidad Complutense de Madrid. España/Spain \\ anavicenteolmo@gmail.com
}

Recibido / Received: 27/07/2016

Aceptado / Accepted: 22/12/2016

\section{RESUMEN}

Este artículo indaga en las desigualdades de género que existen dentro del vínculo amoroso heterosexual en relación al "trabajo emocional" (Hochschild, 1979) a partir de una investigación cualitativa (24 entrevistas en profundidad y 6 grupos de discusión) sobre el amor y las relaciones de pareja entre la juventud española. En una primera parte se reflexiona sobre el concepto de trabajo emocional y sobre cómo identificarlo en las prácticas y dinámicas desarrolladas dentro de la relación de pareja, un ejercicio que permite percibir posteriormente algunos de los aspectos concretos en los que se materializa dicho trabajo en las parejas jóvenes produciendo situaciones de desigualdad que conducen a conflictos, frustraciones femeninas y desconciertos masculinos. Por último, se muestra también cómo las chicas habitan y gestionan este tipo de desigualdad, una tarea fundamental para comprender las tensiones que emergen al contrastar las prácticas cotidianas con los discursos legítimos y modernos del igualitarismo.

Palabras Clave: Género, pareja, trabajo emocional, cuidados, conflictos.

\section{ABSTRACT}

This article delves into the gender inequalities that exist in heterosexual partner relationships in relation to "emotional work", as defined by Hochschild (1979), parting from the analysis of the data obtained from a qualitative investigation (24 in-depth interviews and 6 focus groups) about love and partner relationships between young spaniards. The reflection on the concept of emotional work and how to identify it in the dynamics of a partner relationship enables us to identify some of the specific aspects in which it materializes in young couples, producing situations of inequality that cause conflicts, female frustrations and male bafflement. The analysis of the different ways that women live and handle this type of inequality is fundamental to understand the tensions that emerge when we compare everyday practices and the legitimate and modern discourses of egalitarianism.

Keywords: Gender, relationship, emotional work, care, conflicts.

\footnotetext{
*Autor para correspondencia / Corresponding author: Ana Vicente Olmo. C/ Tomás Bretón, n. ${ }^{\circ} 49$ A, 4. ${ }^{\circ}$ B. 28019 Madrid, España.

Sugerencia de cita / Suggested citation: Vicente Olmo, A. (2018). "Detalles", frustraciones y desconciertos: El trabajo emocional en las parejas jóvenes heterosexuales. Revista Española de Sociología, 27 (1), 67-81.

(Doi: http://dx.doi.org/10.22325/fes/res.2018.4)
} 


\section{INTRODUCCIÓN}

En la España actual, como en el resto de países occidentales, la pareja suele ocupar un lugar prioritario en la vida personal y emocional de la persona adulta y se ha convertido en una de las piezas claves en la obtención de la tan ansiada felicidad (Alberdi, 1999: 114), 0 al menos en el imaginario colectivo. Esta hipertrofia de sus funciones afectivas (Camarero, 2003), que resalta el logro y el objetivo de la felicidad y que toma la pareja como un proyecto vital de realización personal, no puede explicarse sin la expansión de los valores igualitarios. La tendencia a esperar que el amor sea más expresivo y emocionalmente satisfactorio se relaciona directamente con el hecho de que ahora hombres y mujeres tenemos menos motivos económicos para unir nuestras vidas, una situación que incuestionablemente presiona y modifica el ideal de amor hasta poner en el centro de su definición el bienestar emocional de los miembros de la pareja (Hochschild, 2008: 183).

Pero si bien las expectativas sobre este vínculo íntimo hablan de calidez, intimidad e igualdad, el qué ocurre en las interacciones cotidianas de las parejas heterosexuales con respecto a estas cuestiones es un terreno abierto a la especulación. Distintas autoras han afirmado que existe un sistema de intercambio emocional asimétrico entre hombres y mujeres en el contexto de esta relación (Verdú, 2013; Benjamin, 2011; Langford, 1996; Hite, 1995, Duncombe y Marsden, 1993), un hecho que genera conflictos en base a esas expectativas altas que implican el cuidar y "mimar" el vínculo y a la otra persona de forma recíproca, especialmente entre la población joven ${ }^{1}$ (Verdú, 2013). ¿Qué ocurre entonces en el día a día de las parejas? ¿Por qué distintas voces feministas siguen señalando el amor como un terreno en el que persisten desigualdades de género difíciles de percibir? ¿En qué aspectos específicos se concretan estas desigualdades y por qué es complicado apreciarlas y reconocerlas? Y

1 Según Verdú (2013: 176) existen diferencias estructurales por edad en la forma en la que se valora el intercambio de cuidados emocionales en la relación: para la gente joven es más importante esta igualdad. por último, ¿cuáles son las consecuencias de este intercambio emocional asimétrico y cómo se habita 0 gestiona en la relación de pareja? El presente artículo pretende contribuir a responder a estas preguntas, 0 al menos ayudar a clarificar la dirección de los caminos a tomar para ello, a partir de una serie de reflexiones teóricas y del análisis del material empírico producido en una investigación cualitativa sobre las representaciones y las prácticas amorosas de la juventud española².

Para comenzar a responder a estas preguntas dedicamos un primer apartado a explicar qué es el "trabajo emocional" (Hochschild, 1979) en la relación de pareja, un ejercicio teórico y de reflexión que nos va a permitir en un segundo apartado analizar algunos de los aspectos concretos en los que se materializa ese trabajo produciendo lo que algunas autoras han denominado "desigualdad emocional" (Duncombe y Marsden, 1993), una labor necesaria ahora que la dimensión emocional ha adquirido un lugar tan prioritario en el ideal amoroso. Y por último, en el tercer apartado, mostraremos cómo se habita y gestiona en las parejas jóvenes este tipo de desigualdad escurridiza, prestando una especial atención a las tensiones que emergen al contrastar las prácticas cotidianas con los discursos legítimos y del igualitarismo. Y es que aunque, efectivamente, se han producido transformaciones relevantes en cuanto a la mayor emocionalidad que rodea al vínculo íntimo y a las expectativas de reciprocidad e igualdad que lo envuelven, es necesario examinar qué ocurre en sus rutinas, pues son varias las voces que afirman que los cambios han sido mayores en el plano de los ideales y discursos que en el de las prácticas efectivas (Verdú 2013; Benjamin, 2011; Jamieson, 1999).

Antes de concluir esta introducción es preciso señalar algunas cuestiones en relación a la metodología empleada. El diseño muestral ha incluido un total de 24 entrevistas en profundidad y 6 grupos de discusión con jóvenes españoles, heterosexuales y de clase media. La investigación se ha reducido

2 Esta investigación dio lugar a la tesis doctoral Representaciones y prácticas del amor entre la juventud española, defendida por la misma autora del texto en septiembre de 2015 en la Universidad Complutense de Madrid. 
a personas nacidas en España para aminorar la mayor complejidad cultural que aportaría el sumar a los jóvenes migrantes; a heterosexuales porque reducir la muestra a sólo esta orientación sexual permitía una consideración más precisa del impacto del género en la vivencia del amor; y a jóvenes de clase social media ${ }^{3}$ porque no se podía asumir la mayor complejidad de la muestra que hubiera supuesto el contemplar la variable de clase social ${ }^{4}$. Por tanto, las variables que principalmente han estructurado el diseño de la muestra han sido el tipo de hábitat, el género (12 entrevistas y 3 grupos cada colectivo) y la edad (20-29 años, diferenciando las franjas 20-24 y 25-29). Como la investigación concernía al conjunto de la juventud española se decidió escoger 3 lugares como representantes de distintos tipos de hábitat: una gran urbe (Madrid), una ciudad mediana con pautas de comportamiento más tradicionales (Murcia ${ }^{5}$ ) y un pueblo menor de 5000 habitantes situado en un área rural del interior de Castilla-La Mancha, llevando a cabo un total de 8 entrevistas en cada uno de ellos y los grupos de discusión únicamente en las ciudades. Además, se consideró que en la muestra hubiese

3 La clase media ha sido operacionalizada a través de la combinación de dos criterios: el nivel de estudios de los y las jóvenes (mínimo de formación profesional de grado superior 0 estudios universitarios, terminados 0 en curso) y ocupación de los progenitores (al menos que el padre 0 la madre sean trabajadores cualificados 0 profesionales).

4 La formulación de este diseño no responde a la hipótesis de que la cultura de origen, la orientación sexual o la clase social no tengan una influencia destacable en la vivencia del amor, más bien se sostiene en la afirmación de que hablar de juventud en un sentido general esconde la homogenización de una realidad mucho más heterogénea (Bourdieu, 2000). Por este motivo se ha preferido controlar estas variables a través de su homogenización aunque seamos conscientes de que con ello excluimos de la muestra a una parte importante de la juventud residente en España.

5 La Comunidad Autónoma de Murcia presenta valores por encima de la media nacional en su tasa de natalidad (la tercera más alta de toda España sólo por detrás de Ceuta y Melilla), estando además sus valores de edad media al primer matrimonio y a la maternidad por debajo de la media nacional, justo al contrario de lo que ocurre con los datos relativos a la comunidad de Madrid (CIS, Indicadores Demográficos Básicos, 2015). personas con distintas situaciones de pareja (con 0 sin pareja y con 0 sin convivencia) y ninguna casada 0 con hijos.

\section{HACIA LA DELIMITACIÓN DE UN AMPLIO Y COMPLEJO CONCEPTO: EL TRABAJO EMOCIONAL EN LA RELACIÓN DE PAREJA}

El concepto de "trabajo emocional" fue acuñado por Hochschild en los años setenta y supuso un hito importante en el reconocimiento del papel que juegan los afectos en las relaciones sociales y los vínculos humanos. Esta autora definió el trabajo emocional ${ }^{6}$ como al acto de tratar de cambiar el grado 0 calidad de una emoción, tanto las propias como las de los demás; una práctica que sin duda implica la gestión de los sentimientos y requiere de interés, dedicación y esfuerzo (Hochschild, 1979: 561-562).

Estos desarrollos teóricos y conceptuales sentaron la base de posteriores investigaciones sobre las desigualdades existentes en el terreno de las relaciones de pareja heterosexuales. Duncombe y Marsden (1993) Ilevaron a cabo un conocido estudio donde analizaron el lugar de las emociones en la generación de la intimidad, uno de los componentes fundamentales del amor y que más contribuye al bienestar en la relación de pareja (Sternberg, 1988) en este contexto histórico que postula prioritaria la emocionalidad del vínculo. Alcanzar y mantener intimidad requiere "hacer cosas" ; en este contexto el trabajo emocional implicaría a las

6 Conviene apuntar que otras autoras sostienen una definición de trabajo emocional para referirse a la actitud y el esfuerzo por tratar con los sentimientos de otras personas y no tanto sobre los propios (James, 1989). Recogemos aquí esta cuestión porque quizás esta acepción es la que más conecta con las razones que explican las situaciones de desigualdad emocional que afectan a las relaciones de pareja, tal y como se podrá ver en páginas posteriores.

7 Con "hacer intimidad" Duncombe y Marsden quieren enfatizar que los estados emocionales o sentimientos pueden implicar formas de acción o "trabajo emocional" (1993: 221), aplicando de esta forma el concepto de Hochschild a este aspecto concreto de las relaciones de pareja. 
prácticas necesarias para establecer y conservar unas relaciones íntimas cercanas y cuidar el vínculo y los sentimientos ajenos, lo que incluye la expresión del amor y el cariño, entre otras cuestiones (Duncombe y Marsden, 1993). Pero además de la expresión del afecto, ¿qué otras maneras de actuar construyen intimidad y ayudan a cuidar del vínculo y de la otra persona?

La teoría feminista ha puesto mucho esfuerzo en los últimos años en identificar las prácticas sociales complejas y múltiples en las que consiste el cuidado a los demás así como la ética de responsabilidad que lo sustenta (Tobío, 2012: 399), si bien apenas existen reflexiones que ayuden a desentrañar la especificidad que adquiere este trabajo en un vínculo como el de pareja, donde ese "dar por amor ${ }^{8 "}$ que tanto enmaraña las tareas de cuidados adquiere quizás su máxima expresión. Tal y como explica Cristina Vega (2006), el cuidado a la otra persona requiere un compromiso de actuación activo para la generación de su bienestar y una atención concretada en cuestiones como la escucha o la manifestación de empatía hacia aquello que comparte con nosotros/as. La atención es la intensificación de la conciencia en relación a un objeto o persona y es también una disposición ética en la que intervienen los afectos. Atender es orientarse hacia el/la otro/a, implica una actitud comunicativa en la que se construye una posición desde la que hablar y afectar, lo que comprende acciones diversas como advertir, acercarse, apoyar, comprender, empatizar 0 anticipar, entre otras cuestiones ${ }^{9}$. En definitiva, cuidar es una disposición a atender las necesidades de las otras personas (Bubeck, 1995)

8 Como sintetiza Martín Palomo (2008: 21) a partir de la revisión de numerosos estudios, existe un gran consenso dentro y fuera de los estudios de género en que los cuidados son trabajos, prestados con/por amor, por dinero 0 a cambio de bienes materiales 0 simbólicos, pero trabajo a fin de cuentas. En los cuidados que se ejercen con/ por amor son en los que sin duda se torna más difícil reconocer esas actitudes y prácticas como trabajo.

9 Aunque estas reflexiones fueron desarrolladas por Vega Solís (2006) para el estudio del trabajo de cuidados ejercido a domicilio, considero que muchos de estos planteamientos sirven también para desenmarañar lo que es y lo que implica atender y cuidar a alguien en el plano emocional en el contexto de la relación de pareja. que conlleva una lógica incorporada y asentada a través del tiempo que se manifiesta como lógica en acto (Novo y Arenas, 2008: 6; Bourdieu, 1991).

En este artículo indagamos en cómo se manifiestan esas disposiciones y lógicas a cuidar en el plano emocional de la relación de pareja. Pero antes de pasar a esa tarea conviene apuntar algunas cuestiones. Por un lado, debemos traducir esta argumentación teórica y abstracta a un lenguaje que nos permita captar la materialidad de la vida ordinaria. Por trabajo emocional en la relación de pareja nos referimos a ese conjunto de actitudes y prácticas que se llevan a cabo para que la otra persona se sienta más feliz, segura y apoyada. Al decirle a alguien que se le quiere, elogiar su forma de ser 0 arroparle cuando está triste, entre otros ejemplos, lo que buscamos es que esa persona se sienta mejor. También es trabajo emocional ocuparse de la salud del vínculo, tener una actitud que facilite la resolución de los conflictos o hacer cosas para refrescar y fortalecer la intimidad en la pareja ${ }^{10}$.

Por otra parte y tal y como los estudios feministas nos han advertido, partimos de la premisa de que el género influye fuertemente en el desempeño del trabajo emocional. Las mujeres, en su calidad de personas cuidadoras de los demás y especialistas en la vida privada, trabajan más sobre las emociones ajenas, pues se suelen interesar en mayor medida que los hombres por cómo se sienten las personas de su alrededor y llevan a cabo más atenciones y cuidados para que éstas se encuentren mejor (Hochschild, 2008), muchas veces de forma anticipada sin que medien demandas expresas por parte de esas personas. Y es que las mujeres desarrollan una "ética del cuidado" (Gilligan, 1985) por la que se responsabilizan en mayor medida del

10 La intimidad adquiere un papel tan relevante porque, tal y como se señaló en la introducción, la ideología actual de la relación de pareja contiene una fuerte idea de comunicación emocional (Duncombe y Marsden, 1993: 233). Por tanto, las "reglas de sentimiento" (Hochschild, 2008: 144) que guían las definiciones y significados del amor y la relación de pareja entre la gente joven - esas reglas socialmente compartidas que indican, aunque permanezcan latentes en la mayoría de ocasiones, cómo queremos y debemos tratar de sentir - apuntan en efecto a un vínculo amoroso comunicativo, íntimo y cálido. 
bienestar del otro"11 ; encarnan una predisposición que las suele hacer más receptivas y sensibles a las necesidades de las personas con las que se relacionan. Tal y como se podrá comprobar, este hecho influye en las dinámicas y rutinas de las parejas jóvenes heterosexuales a pesar de la aceptación y defensa de valores igualitarios, generándose así situaciones donde es palpable la existencia de aquello que Duncombe y Marsden (1993) denominaron "desigualdad emocional12".

\section{ESOS INSIGNIFICANTES “DETALLES": FRUSTRACIONES FEMENINAS Y DESCONCIERTOS MASCULINOS}

El esfuerzo que supone mantener una relación amorosa y velar para que haya entendimiento $e$ intimidad es algo que aparece con mucha más insistencia en los discursos femeninos. La afinidad entre el amor y el campo metafórico del trabajo es mayor en los relatos de las mujeres, tal y como también constató Eva Illouz (2009: 274) en su investigación en Norteamérica. En efecto, la idea de que el amor es una construcción que requiere trabajo y dedicación centra mucho menos el debate y la atención

11 Otras reflexiones teóricas que contribuyen a reivindicar la importancia de estas acciones en la vida social provienen de la mano de Julia Varela (2013: 625) y su concepto de capital altruista, el cual desarrolló a partir de su estudio sobre la biografía de varias mujeres feministas en los años 30. El capital altruista implica un modo solidario de entender el mundo y compromiso hacia la otra persona y su bienestar que es fundamental para la calidad de vida y la riqueza de las relaciones sociales, por mucho que haya sido una cuestión socialmente desvalorizada ejercida en mucha mayor medida por las mujeres que por los hombres. Bellah y su equipo (1989: 150) tampoco excluyen la posibilidad de que las mujeres hayan desarrollado una sensibilidad moral específica relacionada con el cuidado y con el hecho de que tradicionalmente han pensado más en términos de relaciones que de individualidad aislada y reivindican la importancia social de estas tareas un tanto intangibles.

12 Un hecho señalado por autoras expertas en este terreno como Hite (1995) o también Jónasdóttir (1993), quienes concluyen cuestiones similares aunque no usen exactamente este concepto. en el caso de los varones jóvenes. Estas alusiones desiguales al esfuerzo que requieren las relaciones de pareja explicarían la sensación entre algunas de las entrevistadas de que ellas "tiran más del carro", pues consideran que invierten más energía en el mantenimiento de este vínculo. El diagnóstico concuerda con la afirmación de Antunes (2007: 614 ) de que en los estadios posteriores de las relaciones, tras la fase del enamoramiento, las mujeres dedican más tiempo a la preservación del vínculo íntimo y por ello emerge entre ellas un fuerte consenso en torno a la idea de que la mayoría de chicos "miran menos por la pareja" (mujer, 25-29 años, grupo de discusión). ¿Pero exactamente en qué suelen emplear más tiempo las chicas? ¿En qué se concreta y materializa ese trabajo?

En ocasiones surgen conflictos en torno a la idea de cómo construir el vínculo a través del tiempo común que la pareja disfruta conjuntamente. Algunas mujeres afirman poner más empeño en compartir el tiempo con sus compañeros y a raíz de ello se generan problemas, pues es común que los varones vivan esta situación como una falta de respeto a su independencia, sentimiento y diagnóstico reforzado y alabado por el marco legitimador de la individualización (Casado, 2014). Estas expectativas divergentes en cuanto a la forma de compartir la vida generan a veces sentimiento de soledad entre las mujeres y la sensación de que efectivamente ellos "miran menos que nosotras... que la mujer, la gran mayoría" (mujer, 20-24 años, grupo de discusión):

"Yo me cabreaba mucho porque él iba a su bola, en ese sentido, porque no quería venir a lo mejor con mis amigos, o porque ponía el trabajo por encima de lo que fuera, entonces a mí eso me enfadaba mucho y él decía que yo siempre quería controlar su vida, y entonces... o sea, nuestra guerra fue esa; luego podíamos discutir 'ah, no sé qué, quita el lavaplatos', pero esos eran males menores, la guerra que había entre los dos era esa: que yo quería atraerle más hacia mi vida y él es que estaba muy metido en la suya, y entonces era muy difícil" (mujer, 27 años).

Uno de los objetivos perseguidos en este artículo es descubrir y entender qué prácticas específicas implica el trabajo emocional dentro del vínculo de 
pareja, y una buena manera de seguir desenmarañando esta opaca cuestión es tirar de la madeja del hilo de los "detalles" hasta revelar la estructura de afectos y cuidados que se enredan en ella. La constante alusión a los "detalles" cuando se habla de la relación de pareja deja constancia de la amplitud y vaguedad de este concepto, pues con una misma palabra se nombran cuestiones muy diversas. Por otro lado, también nos muestra el escaso reconocimiento social de la importancia y valía de ciertas actitudes y comportamientos relacionados con el cuidado de los vínculos humanos y del bienestar ajeno, ya que la propia palabra "detalles" actúa empequeñeciendo aquello de lo que habla. Estos detalles hacen referencia, sobre todo, a un trabajo de generar intimidad y "momentos bonitos" que den sentido a la relación de pareja y permitan sentir conexión y romanticismo; es aquí donde debemos situar las frecuentes referencias a los regalos, las sorpresas o las cenas "especiales", entre otros ejemplos. En efecto, toda esta serie de prácticas pueden englobarse bajo el concepto de trabajo emocional (Hochschild, 1979) en la medida en que persiguen acrecentar el bienestar y la felicidad de la otra persona a través de la manifestación del amor y el cuidado hacia ella. Y como la idea de una relación equitativa, comunicativa y cálida ocupa un lugar fundamental en el imaginario amoroso contemporáneo, las mujeres jóvenes se frustran y se quejan al considerar que sus compañeros son poco "detallistas":

"Pues a ver, un poco por mis amigas, lo que veo que les causa conflicto, que a mí también me lo causa, es, en general, cómo los chicos son muy poco detallistas, quizás menos empáticos, menos comprensivos, menos atentos y tienen discusiones pues por cosas así, por: 'no ha tenido este detalle' o... temas así" (mujer, 26 años).

"Yo por ejemplo a Carlos ahora con el tiempo es romántico pero porque muchas veces yo le he dicho 'joder, es que no tienes detalles, es que...', todo el día hay que estar un poco detrás de ellos, yo creo [...]; yo a veces pues ya te digo, le compraba muchas cosas 0 yo qué sé, organizaba una cena 0 mil historias, le llevaba a ver no sé qué que nunca lo había visto o conseguía unas entradas de un grupo casi a última hora y me lo llevaba de sorpresa, y a él a lo mejor, si no le das un empujón no... que tampoco le vas a decir 'oye organízame algo' pero no sé, un poco de sutileza... yo qué sé" (mujer, 27 años).

Es significativo y sintomático que no se hayan encontrado este tipo de lamentaciones entre los chicos. Algunos de ellos muestran indiferencia ante estos "detalles" porque consideran que son irrelevantes para el funcionamiento y mantenimiento del vínculo. Esta afirmación no niega que la relación de pareja sea una cuestión fundamental para los varones y que haya jóvenes que sí reconozcan la importancia de esos detalles y que los tengan en sus relaciones, como se pudo comprobar en algunas entrevistas. De lo que da cuenta esta constatación es de que quizás la conjunción de la menor centralidad que adquiere la relación de pareja en la identidad masculina, junto al hecho de que los varones tienen menos desarrollado el rol de cuidadores y las habilidades y hábitos de pensar en el bienestar del otro, les lleva a preocuparse menos por estos aspectos de la generación del vínculo íntimo ${ }^{13}$. Este análisis coincide con lo señalado por Duncombe y Marsden (1993: 236): los hombres también necesitan una relación personal íntima y cálida, pero pueden devaluar la importancia de expresar el afecto o estar menos dispuestos a reconocer sus propias necesidades por las dificultades que tienen para aceptar y mostrar sus vulnerabilidades (Tannen, 1993).

Otros jóvenes sí admiten que efectivamente tienen pocos "detalles" con sus compañeras y que han empezado a ser algo más considerados a raíz de las molestias que han ocasionado por esta desatención. Pero tras la modificación de sus acciones se aprecia un aprendizaje torpe que, aunque mejora la situación, no cumple del todo con las expectativas femeninas, pues las chicas anhelan recibir ciertos cuidados que las hagan sentir mejor sin que sea necesario demandarlos de forma explícita. Es

13 Tal y como nos enseña el psicoanálisis, al comprender las dinámicas emocionales de la infancia temprana se entiende el sentido diferencial de la masculinidad y la feminidad y el por qué puede haber una relación entre la estructura de género y la desigual capacidad en y para la intimidad entre hombres y mujeres (Chodorow, 1984; Benjamin, 1996). 
común que los hombres tengan dificultades para entender el deseo de sus parejas por sentirse especiales, en el sentido emocional del término, y cómo esas demandas deben cumplirse de forma tácita y espontánea, no como una respuesta a los requerimientos de ellas (Duncombe y Marsden, 1993: 227). Lo que esperan las chicas es una empatía anticipada e incorporada por parte de sus compañeros que les lleve a actuar para que ellas se sientan mejor y sientan la calidez e intimidad del vínculo que les une. Pero como las actitudes y prácticas hacia el cuidado de las demás personas y de los vínculos se manifiestan como disposiciones encarnadas, en numerosas ocasiones los chicos no son capaces de actuar de la forma que sus compañeras esperan: anticipándose. Este hecho provoca frustración y enfado entre las mujeres e incomprensión y desconcierto entre los varones cuando estalla el conflicto y reciben los reproches y regaños de ellas:

"Hombre, yo es que... mi paciencia es un poco... vamos, es diferente a los demás, así que a lo mejor las cosas que yo veo que no tienen importancia pues o ella o tú, por ejemplo, puedes decir: ‘joder, pero cómo puedes hacer eso', y digo: 'pues si tampoco lo veo tan...', no sé" (varón, 24 años).

"Es una chica normal, pero de vez en cuando le daba ahí... más que histérica como que se enfadaba por motivos que yo no consideraba suficientes para enfadarse" (varón, 26 años).

Como en la investigación de Duncombe y Marsden (1993), los chicos entrevistados tienen respuestas de distinta índole a las demandas de atención y cuidado de sus parejas: hay quienes efectivamente tienen detalles, quienes dan la razón a sus compañeras y tratan de modificar sus comportamientos ("al principio yo era poco detallista, soy un desastre, pero me lo dijo y dije: "joder, es verdad', y se intenta solucionar" (varón, 27 años), quienes admiten tener los mismos sentimientos pese a no saberlos expresar de igual modo, otros que simplemente permanecen desconcertados ante una situación que no terminan de comprender y, por último, quienes se enojan ante la frecuencia constante de los conflictos y "pollos" que ocasionan las "quisquillosas" o "complicadas" de sus novias por "chorradas" o "detalles insignificantes".
Pero esos detalles, ¿son sólo "chorradas" 0 es algo importante? ¿Qué significa su presencia y qué generan? Los detalles denotan una actitud empática de preocupación hacia el bienestar de la otra persona que lleva a hacer cosas (esos "detalles") para proteger y reforzar su bienestar psíquico (Gómez, 2002), pues la empatía y la práctica afectiva son instrumentos fundamentales de potencialización al insertarse la atención en procesos de valorización (Vega, 2006). Las disposiciones que orientan hacia el cuidado de las relaciones y la recepción de las necesidades ajenas quedan con frecuencia (in) definidas y ocultas a través del polisémico y abstracto concepto de "detalle". Esta vinculación de sentido evidencia la escasa conciencia que existe en nuestras sociedades sobre lo que es el trabajo emocional y sobre los beneficios que genera $\longrightarrow 0$ los perjuicios ocasionados en su ausencia-. Y esta falta de reconocimiento agudiza el desconcierto de los varones, los cuales tratan de responder con frecuencia a las demandas femeninas de afecto casi como un sacrificio (Casado, 2014: 68) y no porque hayan incorporado ciertas actitudes y prácticas vinculadas al cuidado de los vínculos humanos y del bienestar emocional ajeno:

"Yo cogía y había fines de semana que venía, le vendaba los ojos y me lo llevaba a una casa rural sin decirle nada, de sorpresa; él nunca hacía nada, 0 sea, él se lo tenías que dar mascado... él... yo es como dije: terminamos porque él se dejó de preocupar por la relación y a mí me dejó de importar que ya no se preocupara; antes yo me preocupaba mucho y hablaba con él y decía 'es que esto, jope, pues a ver si lo llevamos así' pero él: 'ay, si sabes, ya sabes que te quiero, si ya sabes que estoy bien contigo', 'ya, pero necesito que hagas algo', 'pero si ya te he regalado esto', digo: 'pero es que no quiero que me regales cosas, yo quiero que hagas cosas conmigo, no regalos', que los primeros regalos me los hacían mis amigas porque les daba el dinero y les decía 'comprad a María esto', o sea, es que estaba en su mundo de yupi" (mujer, 28 años).

Una última cuestión a introducir en este apartado sobre trabajo emocional es la que hace referencia a las pautas y actitudes que afloran ante la presencia de problemas. Entre las mujeres aparece de forma más 
contundente la necesidad de comunicación verbal en el contexto del conflicto, no sólo orientada a la expresión de las propias necesidades sino también a la búsqueda activa del entendimiento entre las dos personas (Verdú, 2013: 177; Tannen, 1993). En cambio, la menor disposición a hablar en el momento que estalla una discusión es una práctica más generalizada entre chicos ("tenía la manía de cuando discutíamos apagaba el móvil y yo me ponía histérica", mujer, 28 años), una dinámica que reactualiza el "yo-relacional" femenino y el "yo-fortaleza" masculino (Casado y Lasén, 2014). Con frecuencia la reconciliación se logra por medio del acomodo de las mujeres a las necesidades de los hombres y su definición de la realidad, un hecho que termina aminorando y disolviendo el problema e instaurando de nuevo la normalidad. Por tanto, el conflicto se convierte a menudo en un momento que refuerza la autoridad masculina y exige la adaptación ${ }^{14}$ de la mujer para preservar el vínculo (Verdú, 2013: 178):

"Cuando discutimos yo estoy muy callao, yo digo las cosas que tengo que decir, si le parecen bien, bien, si no... suelo ser muy directo y muy sencillo, si es que no me gustan ni los teatros, ni las discusiones, ni los gritos, ni las tonterías" (varón, 28 años).

La menor disposición a hablar es una práctica que reivindica el espacio individual y las propias necesidades en detrimento de las de la otra persona (Verdú, 2013: 177) y denota, en ocasiones, indiferencia o poca responsabilidad ante el desasosiego y angustia de la pareja. En definitiva, hablamos de trabajo emocional porque para lograr la reconciliación se invierte energía y tiempo y el manejo de la situación conflictiva remueve sentimientos con los que hay que lidiar. Y hablamos de desigualdad emocional porque en el contexto del conflicto a menudo se viven situaciones asimétricas en las que las mujeres ponen más esfuerzo en comprender las

14 En su investigación sobre trabajo emocional, silenciamiento y ética en la pareja, Orly Benjamin (2011) también detectó que las mujeres desarrollaban cierto trabajo emocional en sus relaciones a través de silenciar algunas de sus molestias o problemas para preservary proteger la relación de pareja o la identidad masculina de sus compañeros por encima de sus propios deseos 0 necesidades. necesidades de la otra persona y adaptarse a ellas que a la inversa.

No queremos concluir este apartado sin antes hacer una advertencia. Consideramos fundamental recalcar que estas actitudes y prácticas que generan desigualdad y desequilibrios dentro de la relación de pareja no se pueden asociar de forma automática a mujeres y varones, pues el género es mucho más abierto que una serie de rasgos fijos y, además, los modelos de masculinidad han sufrido transformaciones hacia un interés y apertura emocional mayor. Por este motivo sabemos que las dinámicas establecidas en algunas relaciones de pareja heterosexuales son justo las contrarias a las tendencias señaladas aquí. De lo que quiere dar cuenta este análisis es de que pese a esta fluidificación de las identidades y a la constatación de que el género es una cuestión relacional en continuo movimiento (García Selgas, 2012), existe aún una inclinación tendencial mayor por parte de las mujeres al cuidado porque esta actitud es fruto de disposiciones arraigadas que se relacionan con la propia forma en la que se consolida la subjetividad femenina a través del lugar que ocupa en ellas el vínculo (Chodorow, 1984).

\section{JUSTIFICACIONES Y AMBIVALENCIA ALREDEDOR DE UNA DESIGUALDAD ESQUIVA Y MOLESTA}

Si en los anteriores apartados hemos explicado qué es el trabajo emocional y cómo se concreta entre la juventud heterosexual, en éste último nos ocupamos de la tensión que existe entre normas y prácticas en torno a la (des)igualdad en la pareja y su relación con distintas formas de habitar y convivir con esta desigualdad.

Las cuestiones ligadas al trabajo emocional no se viven de manera uniforme entre todas las mujeres jóvenes. En los ámbitos donde existe cierta conciencia feminista sobre las desigualdades de género es más fácil y probable que se problematice el por qué algunas cosas importantes son llamadas "detalles", desvelando así la jerarquía naturalizada que resta valor a este tipo de trabajo emocional y que, en última instancia, no es sino otra muestra de una lógica moderna que expresa y conforma los 
marcos de nuestra experiencia, subordinando los afectos a la razón y denotando así ciertas jerarquías entre órdenes y esferas (Casado, 2014: 66):

"Claro, porque a mí lo que me pasa, a mí lo que me jode mucho es que le damos importancia a cosas muy diferentes; yo en todas mis relaciones le he dado importancia a cosas, a determinados detalles que encima los llamo detalles y a lo mejor son los que hacen la relación y a lo mejor los he seguido llamando detalles cuando son las cosas más importantes" (mujer, 25-29 años, grupo de discusión).

Algunas chicas son conscientes de que los cuidados ejercidos en la pareja suelen generar un bienestar desigual para unos y otras. Esta identificación de las responsabilidades y acciones que conducen al poder en la relación y la superación del sentimiento de culpa es importante para introducir cambios en el sistema de género (Del Valle et al., 2001: 14), pues despierta la conciencia y reflexión sobre algunos aspectos que, de lo contrario, permanecen naturalizados en una mayor medida. El conflicto, al menos, se visibiliza y reivindica.

En cambio, otras mujeres jóvenes necesitan restarle importancia al hecho de no adherirse en sus prácticas cotidianas al ideal hegemónico e incuestionable de la igualdad de género. Estas justificaciones pueden manifestarse a través de la alusión a estereotipos que dan cuenta de unas identidades de género esencializadas que naturalizan y normalizan las diferencias y desigualdades. Pese al calado de la ideología igualitarista, los y las agentes sociales movilizamos con frecuencia un sentido de las identidades genéricas en las que se preserva la diferencia entre varones y mujeres como algo natural, (re) construyendo así las posiciones sociales de varones y mujeres como sustancias (García García, 2009: 298). Los estereotipos facilitan hacer la vista gorda sobre ciertas situaciones y contribuyen a construir el sentido de sí mismos de hombres y mujeres en sus relaciones amorosas (Jamieson, 1999: 491):

"Bueno, a ver, es que, es que para mí... a lo mejor dices: 'mira, eres un poco feminista' [risas], yo que sé, pero los hombres son hombres, y los hombres son un poco limitados y les falta... les falta iniciativa para estas cosas, o lo que hablaba antes: que es que no son tan detallistas como nosotras" (mujer, 26 años).
El uso de estereotipos normaliza y justifica la insatisfacción con los varones, manifestándose así la desigualdad, simultáneamente, como el origen del conflicto y la estrategia para solucionarlo (Verdú, 2013: 179). Es común recurrir a ellos en situaciones sociales de estancamiento en las que se conoce el problema pero no se acaban de articular dinámicas distintas. En estos contextos las generalizaciones estereotipadas suponen un atenuante pasajero que tiene un efecto confirmatorio de esas prácticas cotidianas (Novo y Arenas, 2008: 7).

Otra de las justificaciones que más apareció tras el reconocimiento de que las chicas "dan más" de lo que reciben en la interacción íntima es la alusión a que esta forma de actuar forma parte de su "personalidad". Las disposiciones femeninas de cuidado y entrega son uno de los enclaves sobre los que pivota la identidad femenina, pero muchas de estas jóvenes explican que esta forma de actuar es una característica idiosincrásica de su propia personalidad. El género se (re)hace de una manera pre-reflexiva y por ello la heteronomía que suele aparecer asociada a la feminidad (García Selgas y Casado Aparicio, 2010) es vivida como una disposición relacional de implicación emocional naturalizada: la responsabilidad afectiva hacia las otras personas y su bienestar se incorpora (Vega, 2006) y la justificación empleada permite compensar su imagen dañada al evidenciarse la falta de reciprocidad:

"Yo creo que tanto con Tomás como con Carlos yo he dado siempre más, pero también he de decir que yo soy una persona que da mucho, con la gente, cuando alguien me importa yo lo doy todo, entonces es fácil que yo de más" (mujer, 27 años).

Cómo llegar a cierta coherencia entre las expectativas de reciprocidad y la imagen que las mujeres jóvenes proyectan guarda relación con su posicionamiento ante la igualdad de género. A mayor identificación con este ideal ${ }^{15}$, más empeño por

15 Esta constatación nos alerta de una cuestión metodológica: estudiar la desigualdad entraña ciertas dificultades porque es embarazoso reconocer las desviaciones de una imagen de pareja igualitaria que ejerce presión y atracción. En este sentido, se ha comprobado que es más complicado que las quejas por la asimetría salgan a la luz en una relación de pareja no concluida. 
proteger la visión que dan de ellas y de la relación cuando se evidencian desigualdades. En cambio, cuando esta identificación es menor a esas mujeres les resulta menos incómodo aceptar de forma explícita algunas experiencias:

"Que va, él a mí nada, yo le escribía 1000 mensajes súper bonitos, yo me pasaba la vida en plan esto de que quedas para cenar 0 sales y luego llegas a casa y escribes un mensaje 0200 y él no me contestaba nunca, alguna vez, pero en plan..." (mujer, 24 años).

La chica del ejemplo anterior, alejada de la ideología igualitaria, expresa un profundo malestar por la situación de desigualdad vivida pero duda de la legitimidad de sus quejas. Se queda atrapada en el desconcierto, pues no es capaz de posicionarse ante la situación y termina culpándose por generar conflictos y el fin de la relación.

Pero este sentimiento de culpa no sólo emerge entre las menos progresistas. Las mujeres son las que en mayor medida inician las discusiones y las que se enfadan con más frecuencia, una cuestión que asumen y reconocen tanto ellas como ellos. Pero si bien es apreciable este rol "guerrero" y quejoso, la vivencia y expresión del enojo está atravesada por algunas contradicciones que van más allá de la identificación con los valores del igualitarismo. Algunas chicas se enfadan por ciertos aspectos de su relación de pareja pero viven con ambivalencia esos disgustos y conflictos. Asumen que tienen problemas por la desigual implicación en el cuidado de la relación, pero no sin sentirse en ocasiones "pesadas" por ser ellas las que siempre inician la discusión. El querer alejarse de la imagen de feminidad vinculada a ese lugar y posición incómodos de la que solicita reiteradamente cosas insignificantes y atención (Casado, 2014), les lleva a veces a relativizar sus molestias, quejas y demandas. En cambio, ellos suelen estar conformes con las atenciones que reciben y en el nivel interactivo esta ambivalencia implícita les protege de la ira de sus compañeras (Benjamin, 2011).

Por otro lado, la escasa conciencia sobre lo que es el trabajo emociona ${ }^{16}$ también contribuye

16 Por ejemplo, el trabajo doméstico ya es reconocido por un amplio sector de la sociedad como un trabajo a generar ambivalencia alrededor de los enfados femeninos ${ }^{17}$. La falta de reconocimiento social del papel que tiene el trabajo emocional en el mantenimiento de los vínculos y en la generación de bienestar no sólo contextualiza los desconciertos de ellos, pues las mujeres tienen dificultad para afirmar con seguridad, poder y autoridad que esta cuestión es fundamental para el vínculo y para la reciprocidad deseada en él. Tal y como explica Fishman (1982: 397), el poder opera de diversas formas en una relación pero una de ellas es a través de imponer la definición propia de la realidad, de lo que es posible, lo que está bien o lo que es racional y lógico. Por tanto, es importante atender a las desigualdades de autoridad que existen en las relaciones de pareja heterosexuales, pues la autoridad suele asociarse con más frecuencia a la masculinidad y ello genera diferencias en la capacidad de control y coerción dentro de las relaciones (Connell, 2009):

"Yo se lo decía, le decía: 'si es que..', yo era de decirlo, yo le decía: 'si es que de verdad...', lo que pasa es que él le quitaba tanta importancia... yo hubo un momento... mira, él le quitaba tanta importancia y lo hacía tan simple que yo hubo un momento que dije 'pues esto es así', y yo después, cuando conocí a los demás tíos con los que he estado me he dado cuenta de que no, de que las cosas no son así" (mujer, 24 años).

necesario y fundamental para el mantenimiento de la vida, pero no ocurre lo mismo con el trabajo puramente emocional, pues se desarrolla en un ámbito escurridizo que dificulta captar de qué se trata y qué beneficios genera. Esta cuestión de la imperceptibilidad que rodea al trabajo emocional es importante porque cuanto más se reconoce e identifica una tarea como tal, resulta más sencillo -0 al menos legítimo- el manejo de las situaciones conflictivas que afloran en la cotidianidad.

17 Benjamin (2011) resalta también la ambivalencia con la que las mujeres viven los arranques de ira con sus compañeros: se enfadan pero al poco tiempo encuentran motivos que restan importancia a su malestar y terminan haciendo más esfuerzo por comprender empáticamente la situación de ellos; es un ejemplo de cómo el orden de la interacción pasa con frecuencia por la adaptación femenina a la situación (Casado, 2014: 65). 
Esta cuestión no es baladí porque produce perjuicios para las mujeres, las cuales no sólo suelen recibir menos cuidados ${ }^{18}$ de los que dispensan sino que, además, viven con problemas este malestar; y es que cómo expresar y nombrar sus sinsabores y quejas, incluso enfadarse, por algo tan insignificante que ni tiene nombre, esos simples "detalles". Esta falta de legitimidad para vivir y habitar el enfado se ve avalada por el contexto de individualidad reflexiva en que vivimos, el cual convierte el respeto al otro y la otra y a sus deseos y ritmos (Casado, 2014) en un punto crucial del "contrato" de la pareja, un hecho que refuerza también la ambivalencia. La mezcla de este contexto individualizado con la centralidad que adquiere la relación de pareja en la vida de las mujeres deja a las chicas, en ocasiones, en una posición complicada para relacionarse en el terreno afectivo al sentir que sus deseos de implicación emocional e intimidad tienen que combinarse con esa presión por el respeto de la individualidad de la otra persona:

“¿Desequilibrio? Sí, creo que yo me vuelco más que las personas con las que he estado hasta ahora; tampoco es algo que pueda reprochar como decía antes porque cada uno da lo que puede dar, ¿no?, pero sí es verdad, yo al principio por ejemplo le escribía más, 0 le llamaba más 0 habría pasado más tiempo con él y él es de otra manera, él si te escribe un email te escribe una línea, nunca te envía una carta, no creo que nunca te envíe una postal, nunca vino a verme, por ejemplo... desequilibrios, sí, igual ahí está el error" (mujer, 27 años).

Para algunas chicas es incómodo explicitar un enfado por falta de reciprocidad porque ello las devuelve a una posición identitaria rígida y tradicional que les produce rechazo. Esta situación resulta algo paradójica porque las incomodidades se tornan un

$18 \mathrm{El}$ porcentaje de varones y mujeres que dicen acudir a su pareja 0 cónyuge en el caso de que necesiten ser cuidado/a por caer enfermo/a es de $57,9 \%$ y $43,0 \%$, respectivamente. La diferencia entre porcentajes es aún más notoria cuando se trata de necesitar "hablar en caso de tener problemas, sentirse triste 0 deprimido/a", pues el 53,8 \% de los varones dice acudir a su pareja o cónyuge frente al 32,1 \% de mujeres (CIS, 2016). tanto invisibles en el contexto "libre" del igualitarismo, pues tal y como afirma Illouz (2012: 195), el fundamento de la libertad contractual que rige en la actualidad las relaciones afectivas vuelve más confusa la atribución de responsabilidades.

En síntesis, en este epígrafe queríamos mostrar que las vivencias femeninas de los conflictos que surgen a raíz de la desigualdad emocional están rodeadas de contradicciones por la presión que ejerce la imagen deseada de pareja igualitaria. El diálogo con el ideal incuestionable de la igualdad genera adaptaciones dispares en función de los contextos y las subjetividades de género: desde la reivindicación del enfado y la superación del sentimiento de culpa entre las mujeres con posicionamientos políticos feministas más explícitos, al uso de estereotipos u otras justificaciones entre aquellas chicas que se identifican con los valores igualitarios y que sienten incomodidad al desvelar algunos rasgos de sus relaciones de pareja, sin olvidar las pocas que reconocen sin pudor la desigualdad vivida. Pero más allá de estas diferencias, es importante resaltar que un aura ambivalente suele rodear los malestares e irritaciones de las mujeres, pues es habitual que comiencen expresando quejas pero luego terminen dudando 0 cuestionando la legitimidad de sus propias demandas. A todo ello contribuye, sin duda, el hecho de que el trabajo emocional sea un terreno muy resbaladizo de difícil reconocimiento tanto para quien lo realiza como para quien lo recoge. Las distintas tareas de cuidados recogidas bajo el amplio y difuso concepto de "detalles" generan bienestar y potenciación en la persona que las recibe, pero esta falta de reconocimiento vuelve imperceptibles los beneficios y perjuicios que se enredan en este intercambio asimétrico de atenciones y (des)consideraciones. Estas dificultades que existen para identificar, nombrar 0 incluso entender en qué consiste este tipo de trabajo que tanto tiene que ver con las disposiciones a cuidar, influyen también en la forma de vivir las situaciones que se crean a su alrededor, pues los malestares y conflictos son encarados desde la contradicción 0 una legitimidad escurridiza que torna ambivalentes las quejas y demandas femeninas y contribuye al desconcierto de los varones. 


\section{CONCLUSIONES}

El presente trabajo ha querido contribuir a explicar por qué la relación de pareja es señalada por distintas voces feministas como uno de los espacios en los que más desigualdades de género persisten. Nos hemos centrado en el análisis de la interacción emocional porque investigaciones previas habían afirmado la existencia de un intercambio asimétrico en este aspecto en el contexto del vínculo amoroso entre hombres y mujeres (Verdú, 2013; Benjamin, 2011; Langford, 1996; Hite, 1995, Duncombe y Marsden, 1993) y queríamos profundizar en su comprensión. Para ello, hemos reflexionado sobre cómo adaptar y entender el concepto de "trabajo emocional" (Hochschil, 1979) en la relación de pareja, un trabajo que da cuenta de aquellas actitudes y acciones que se orientan al manejo de los sentimientos para fortalecer el vínculo y el bienestar de/de la compañero/a. El uso de este concepto puede entenderse como una propuesta analítica útil para captar y repensar los distintos tipos de cuidados. Si ya supuso un gran avance empezar a hablar de trabajos de cuidados, el trabajo emocional es una herramienta conceptual especialmente adecuada para apuntar directamente a esos elementos materiales, afectivos y morales (Martín, 2008: 21) que se enredan en el manejo de las emociones pasando desapercibidos, una tarea especialmente importante en el ámbito de la relación de pareja porque es probablemente el terreno en el que menos se ha estudiado aún esa barrera difusa entre amar, cuidar y "trabajar".

Los resultados de esta investigación muestran que es habitual que el trabajo emocional se realice de manera desigual en las parejas jóvenes españolas. En general, las chicas ponen más interés y esfuerzo en hacer cosas o tener "detalles" que contribuyan a alimentar la intimidad en el vínculo y potenciar la dicha de la otra persona. Tras los regalos, las sorpresas 0 la expresión del amor en cartas y notas (los famosos "detalles") lo que se encuentra es una disposición incorporada por la que se hacen cosas por el vínculo y por la otra persona sin que medien demandas explícitas por la contraparte, pues la disposición hace que se actúe y piense con anticipación (Vega, 2006). A veces esta situación despierta conflictos porque las expectativas sobre la calidad emocional de la relación de pareja son altas entre la población joven e implican reciprocidad e igualdad: se espera que hombres y mujeres cuiden y "mimen" por igual. Pero a pesar de esta transformación de la dimensión reguladora de las relaciones afectivas y de las relaciones de género, en el nivel de las prácticas afloran matices que complejizan esta imagen un tanto simplista de la pareja cálida, comunicativa e igualitaria.

Como el mantenimiento y cuidado de los vínculos adquiere un lugar distinto en los modelos de masculinidad y feminidad (Baker, 1992), con frecuencia las mujeres jóvenes son más proactivas y se muestran más receptivas a las necesidades ajenas. El material empírico ha constatado que las chicas se quejan más que los varones por descuidos y desconsideraciones de sus compañeros hacia ellas o hacia la relación, pues generalmente ellos "tienen menos detalles" y ellas "tiran más del carro". Pero lo verdaderamente interesante es resaltar la ambivalencia que genera en ellas estas vivencias frustrantes. Ante la experiencia cotidiana surgen estrategias dispares de adaptación que van desde la asunción del "modelo masculino" más desapegado (Hochschild, 2008) a la reivindicación de que lo necesario es que ellos se sumen en igualdad a ese trabajo común por la relación y por tener en cuenta a la otra persona, pasando por vías que median entre una y otra opción: aunque se sigan expresando quejas se rebajan las expectativas y se termina "tirando la toalla". Las estrategias para habitar, entender 0 justificar esta desigualdad son por tanto múltiples, desde el recurso a estereotipos de género que naturalizan esta diferencia hasta convertirla en un hecho irremediable que hay que aceptar en la relación heterosexual, a la negación de esa desigualdad o su justificación apelando a motivos ajenos al género. Las posturas de los chicos también son variadas: muchos reconocen el hecho de que ellos son menos "detallistas", "desconsiderados" 0 "más desastres", pero otros en cambio muestran confusión ante las demandas de atención y cariño de sus compañeras o se enojan. Interacciones ordinarias que hablan de frustraciones femeninas 
y desconciertos masculinos en relaciones de pareja supuestamente igualitarias; frustraciones en tanto que el acomodo entre los géneros es más molesto (Goffman, 1977) con la expansión del igualitarismo y desconciertos ante el reclamo de una heteronomía de difícil comprensión y encarnación desde la posición de varón.

Estos hallazgos y reflexiones enriquecen el debate sociológico contemporáneo sobre la transformación de los vínculos de pareja. Prestigiosos investigadores han enfatizado el cambio producido entre los roles y experiencias de género en la relación íntima en los últimos tiempos (Giddens, 1995). Aunque estas afirmaciones no son falsas es preciso matizarlas, pues el reconocimiento de las mujeres como sujeto productivo, político y deseante (Casado, 2014: 60) no supone automáticamente el derrumbe de las disposiciones de género que articulan las interacciones. Los datos recogidos demuestran que más allá de la racionalización y la reflexión, la relación de pareja se sostiene sobre unos habitus de género (McNay, 2000) que inclinan y posicionan a mujeres y hombres de manera desigual hacia el vínculo y el cuidado, lo que incluye también los hábitos comunicativos y empáticos hacia/con la otra persona, algo que supuestamente es muy importante realizar de forma recíproca y equitativa en el ideal de pareja actual. Los ejemplos mostrados han tratado de captar y perseguir una incomodidad y unas tensiones escurridizas pero arraigadas en las relaciones de pareja heterosexuales. Estrechar los malestares y desconciertos ayuda a completar 0 matizar el retrato de las parejas igualitarias (Casado, 2014), pues la comprensión mayoritaria se sostiene en la idea de que las diferencias de género ya no son importantes porque las dos personas de la pareja son individuos libres, pero las mujeres y los hombres hablan, piensan e interactúan en la relación amorosa dentro de un marco donde el género sigue ejerciendo una influencia considerable (Benjamin, 2011: 7).

Este es uno de los motivos que explica precisamente la pervivencia de una desigualdad que es tan obstinada como difícil de comprender y reconocer: más allá de la expansión de expectativas igualitarias en torno a lo que mujeres y hombres desean dar y recibir en su relación de pareja, en el vínculo amoroso se enredan diferencias y desigualdades porque éstas descansan más en la propia dinámica de la configuración de las identidades de género que en la concienciación y reflexión sobre el deseo de igualdad.

De hecho y paradójicamente, la propia extensión del igualitarismo dificulta en ocasiones detectar las desigualdades que aún persisten, pues con él se vuelve más embarazoso su reconocimiento. Esta cuestión es especialmente importante en el vínculo de pareja porque la buena salud de éste es casi su única justificación: en un momento en el que la relación de pareja responde sólo teóricamente a la continuidad del amor y de los beneficios que aporta la relación, los conflictos, frustraciones o sinsabores pueden comprometer nuestra imagen (Casado, 2014). Es más, lo que detectamos es que, en concordancia con lo ya señalado por Beck y Beck-Gersheim (1998) 0 Jamieson (1999), a veces son las propias narrativas amorosas las que contribuyen al mantenimiento 0 la ocultación de algunas desigualdades de género en la pareja al tender a aminorar el conflicto en aras de la complementariedad. Y es que el vínculo de pareja y la vida íntima, más que disolver los procesos de diferenciación, son quizás el espacio en que cobran más fuerza las diferencias de género y su naturalización (Goffman, 1977).

\section{AGRADECIMIENTOS Y FINANCIACIÓN}

Este trabajo forma parte de una investigación doctoral realizada en el marco del programa de Formación de Personal Universitario (FPU) del Ministerio de Educación, Cultura y Deporte. Agradezco a este Ministerio y a la Universidad Complutense de Madrid la financiación y recursos prestados a lo largo de todo este tiempo.

\section{REFERENCIAS BIBLIOGRÁFICAS}

Alberdi, I. (1999). La nueva familia española. Madrid: Taurus.

Antunes das Neves, A. S. (2007). As mulheres e os discursos genderizados sobre 0 amor: a caminho do 'amor confluente' ou o retorno ao mito do 
'amor romantico'. Estudios Feministas Florianópolis, 15 (3), 609-627.

Baker, J. (1992). Hacia una nueva psicología de la mujer. Barcelona: Paidós.

Beck, U., Beck-Gersheim, E. (1998). El normal caos del amor. Barcelona: El Roure.

Benjamin, J. (1996). Los lazos del amor. Psicoanálisis, feminismo y el problema de la dominación. Madrid: Paidós.

Benjamin, 0. (2011). Gender and contesting models of love: Ambivalence as silencing in israeli intimate relationships. I Global Conference: Gender \& Love, Oxford: Mansfield College.

Bourdieu, P. (1991). El sentido práctico. Madrid: Taurus Humanidades.

Bourdieu, P. (2000). Cuestiones de Sociología. Madrid: Istmo.

Bubeck, D. E. (1995). Care, Gender and Justice. Oxford: Clarendon Press.

Camarero, M. (2003). El conflicto cultural entre modelos de relaciones familiares. En E. Bericat, (coord.), El conflicto cultural en España. Acuerdos y desacuerdos entre los españoles (pp. 136-203). Madrid: CIS.

Casado, E. (2002). La construcción socio-cognitiva de las identidades de género de las mujeres españolas (1975-1995). Tesis doctoral, Universidad Complutense de Madrid.

Casado, E. (2014). Tramas de género en la comunicación móvil en pareja. En A. Lasén y E. Casado (eds.), Mediaciones tecnológicas. Cuerpos, afectos y subjetividades (pp. 55-72). Madrid: UCM y CIS.

Casado, E., Lasén, A. (2014). What is disturbing and why not to disturb. On mobile phones, gender, and privacy within heterosexual intimacy. Mobile Media \& Communication, 2 (3), 249-264.

CIS (2016). Barómetro de febrero 2016 (Estudio 3.128) (en línea). http://www.cis.es/cis/open$\mathrm{cms} /$ ES/busqueda.html

Connell, R. (2009). Gender in world perspective. Cambridge: Polity.

Chodorow, N. (1984). El ejercicio de la maternidad. Barcelona: Gedisa.

Del Valle, T., Apaolaza, J. M., Arbe, F., Cucó, J., Díez, C., Esteban, M. L., Etxeberria, F., Maquieira, M. (2001). Modelos emergentes en los sistemas y las relaciones de género. Madrid: Narcea.
Duncombe, J., Marsden, D. (1993). Love and intimacy: the gender division of emotion and 'emotion work': A neglected aspect of sociological discussion of heterosexual relationships. Sociology, 27 (2), 221-241.

Fishman, P. M. (1982). Interaction: The Work Women Do. Social Problems, 25, 397-406.

García García, A. A. (2009). Modelos de identidad masculina: representaciones y encarnaciones de la virilidad en España (1960-2000). Tesis doctoral, Universidad Complutense de Madrid.

García Selgas, F., Casado Aparicio, E. (2010). Violencia en la pareja: género y vínculo. Madrid: Talasa.

García Selgas, F. (2012). Género, rol e identidad: una aportación del feminismo a la teoría social. En E. Bericat (ed.), Sociologías en tiempo de transformación social (pp. 139-160). Madrid: CIS.

Giddens, A. (1995). La transformación de la intimidad. Sexualidad, amor y erotismo en las sociedades modernas. Madrid: Cátedra.

Gilligan, C. (1985). La moral y la teoría. Psicología del desarrollo femenino. México: Fondo de Cultura Económica.

Goffman, E. (1977). The arrangement between the sexes. Theory and Society, 4 (3), 301-331.

Gómez, G. (2002). Hombres y mujeres: el difícil camino hacia la igualdad. Madrid: Editorial Complutense.

Hite, S. (1995). Informe Hite sobre mujeres y amor. Barcelona: Paidós.

Hochschild, A. (1979). Emotion Work, Feeling Rules and Social Structure. American Journal of Sociology, 85 (3), 551-75.

Hochschild, A. (2008). La mercantilización de la vida íntima. Apuntes de la casa y el trabajo. Buenos Aires: Katz.

Illouz, E. (2009). El consumo de la utopía romántica. El amor y las contradicciones culturales del capitalismo. Buenos Aires: Katz.

Illouz, E. (2012). Por qué duele el amor. Una explicación sociológica. Madrid: Katz.

James, N. (1989). Emotional Labour: Skill and Work in the Social Regulation of Feelings. The Sociological Review, 37 (1), 15-42.

Jamieson, L. (1999). Intimacy transformed? A critical look at the 'Pure relationship'. Sociology, 33 (3), 477-494. 
Jónasdóttir, A. (1993). El poder del amor. ¿Le importa el sexo a la democracia? Madrid: Cátedra.

Lakoff, G., Johnson, M. (2001). Metáforas de la vida cotidiana. Madrid: Cátedra.

Langford, W. (1999). Revolutions of the heart. Gender, power and the delusions of love. London/ New York: Routledge.

Martín Palomo, M. T. (2008). Domesticar el trabajo: una reflexión a partir de los cuidados. Cuadernos de Relaciones Laborales, 26 (2), 13-44.

McNay, L. (2000). Reconfiguring the subject in Feminist and Social Theory. Cambridge: PolityPress.

Novo, M. A., Arenas, M. (2008). Mediaciones sociales que comprometen al amor en los jóvenes. Revista Digital Universitaria, 9 (11), 1-13.

Sternberg, R. (1988). The Triangle of Love: Intimacy, Passion, Commitment. New York: Basic Books.

Tannen, D. (1993). Tú no me entiendes. ¿Por qué es tan difícil el diálogo hombre-mujer? Buenos Aires: Editor S. A. Javier Vergara.

Tobío, C. (2012). Cuidado o identidad de género. De las madres que trabajan a los hombres que cuidan. Revista Internacional de Sociología, 70 (2), 399-422.
Varela, J. (2013). La larga lucha por la emancipación de las mujeres. Carmen Baroja y Nessi, Zenobia Camprubí Aymar y María Teresa León Goyri. Papers, 98 (4), 611-627.

Vega Solís, C. (2006). Subjetividades en tránsito en los servicios de atención y cuidado. Aproximaciones desde el feminismo. Barcelona: Diputación de Barcelona.

Verdú, A. D. (2013). Género y conflicto en las relaciones de pareja heterosexuales: la desigualdad emocional. Cuestiones de género: de la igualdad y la diferencia, 8, 165-18.

\section{NOTA BIOGRÁFICA:}

Ana Vicente Olmo pertenece al Grupo de Estudios Socio-Culturales Contemporáneos (GRESCO) de la Universidad Complutense de Madrid (España). Licenciada y Doctora en Sociología por la Universidad Complutense de Madrid y Máster en Análisis Sociocultural de la Comunicación y el Conocimiento en esta misma universidad. Áreas de investigación principales: estudios de género, especialmente en el terreno de la intimidad y la pareja, y determinantes sociales y desigualdades en salud. 
